\title{
Solid Waste Management in a Mexican University Using a Community- Based Social Marketing Approach
}

\author{
Carolina Armijo-de Vega ${ }^{*}, 1$, Sara Ojeda-Benítez ${ }^{2}$, Quetzalli Aguilar-Virgen ${ }^{1}$ and \\ Paul A. Taboada-González ${ }^{1}$
}

\author{
${ }^{I}$ Facultad de Ingeniería Ensenada, Universidad Autónoma de Baja California, Km 103 Carretera Tijuana-Ensenada, \\ Ensenada, Baja California. México C.P. 22870 \\ ${ }^{2}$ Instituto de Ingeniería, Universidad Autónoma de Baja California, Blvd. Benito Juárez y Calle de la Norma S/N, 21280 \\ Mexicali B.C. México
}

\begin{abstract}
Waste separation and recycling programs in higher education institutions requires an approach that reach people in different ways. Social marketing approach has proved to be effective in helping reach the desired change for very different initiatives. In this paper is presented a sixteen month experience of a paper and cardboard separation program at the Ensenada Campus of the Autonomous University of Baja California (UABC). Although the support from the University authorities is important, through different experiences it was found that in UABC the programs that work better are the ones that do not depend on the work of personnel but on the participation of students and academic staff. To gain this participation the strategies used in social marketing were used. To date through UABC's paper and cardboard program the institution has diverted more than six tons of this type of waste from the main waste stream. Based on the evaluation of the program and on the increasing community response, it can be said that the social marketing strategies used in this program were successful.
\end{abstract}

Keywords: Social marketing, solid waste, recycling.

\section{INTRODUCTION}

In the XXI century higher education institutions have to face a series of challenges such as the promotion and implementation of sustainable practices through the participation of faculty, students and staff, which should be compromised in building a better future for the generations to come. Diverse research have shown that the role that universities and their faculty play when promoting sustainable practices is key and influences the success of other sustainability programs in society [1-5]. In addition, several universities worldwide have incorporated the sustainability approach to their courses and academic programs to form professionals sensible to environmental protection [1, 6-8]. Education and formation of new professionals must include the sustainable approach as to acquire the necessary skills to face diverse environmental problems. In this sense, universities should put into practice strategies for sustainable development which must be immersed in their academic programs, research, outreach, and facilities operation. One of the many environmental problems that must be addressed is the one related to the increasing amounts of solid waste.

Internationally, municipalities are challenged every day with the complexity of solid waste management; the increasing generation of waste, the limited resources

*Address correspondence to this author at the Facultad de Ingeniería Ensenada, Universidad Autónoma de Baja California, Km 103 Carretera Tijuana-Ensenada, Ensenada, Baja California, C.P. 22870, México; Tel/Fax: 52(646) 174-4333; E-mail: carmijo@uabc.edu.mx available for its management and the lack of responsibility from waste generators worsen the problem. This implies that problems generated as a consequence of the improper management of municipal solid waste (MSW) are complex because waste is generated in diverse sectors such as commercial (stores), education (schools), health (hospitals), recreation (parks), and touristic (hotels), among others. These establishments are heterogeneously distributed in the cities and have different performance contexts as well. This diversity of waste generators makes very difficult to implement effective and efficient waste management initiatives. To face this complexity in the management of MSW some countries have put into practice sector-tailored solid waste strategies. In this way, waste generators of the same section or sector, for example the hotel section, get organized and create common plans for waste management that includes common practices for the segregation by waste type, for temporal storage, transport and treatment. Through this organization the responsibility of waste management is shared among the same section generators.

To achieve sectional waste management plans first is necessary to know the characteristics of waste that each section generates and the approximate amounts. Also it is necessary to implement waste management pilot programs to detect and correct possible failures and to add new practices that could improve the program in each section. In this sense, recent research carried out in different parts of the world show that colleges and universities are not aside from the problems related with waste generation. For this reason some institutions have involved in waste management programs with the objective to recover the recyclable materials [9-11], 
in the implementation of zero waste programs in university campus [12], and on recovering of paper [13]. Moreover, some educational institutions have also engaged in the promotion of a new conception of man and nature through a change in attitudes, culture and consciousness; in this sense a research was carried out to know the attitudes and behavior towards recycling in a university campus [10].

It is also important to mention that in education institutions waste composition is different from household waste; Table 1 shows the differences in composition by weight of these two generation sources.

Table 1. Waste Composition in Education Institution and Households

\begin{tabular}{|c|c|c|}
\hline Type of Waste & $\begin{array}{c}\text { Education Institutions } \\
\text { (Percentage of } \\
\text { Total Waste) }\end{array}$ & $\begin{array}{c}\text { Households } \\
\text { (Percentage of } \\
\text { Total Waste) }\end{array}$ \\
\hline \hline Paper and cardboard & $20-50 \%{ }^{\mathrm{I}}$ & $11-20 \%{ }^{\mathrm{II}}$ \\
\hline Organics & $20-48 \%{ }^{\mathrm{III}}$ & $22-55 \%{ }^{\mathrm{III}}$ \\
\hline
\end{tabular}

Observing these differences it is imperative to know the quantities and characteristics of waste generated in each section before proposing sectional waste management plans; this is also valid for the school section.

Different experiences have shown that the logistics and technology alone are not enough for a recycling program to be successful because the human factor plays a key role. Thus, an important component of any recycling program is the communication and information campaign that seeks to reach the people intended to participate. In the Autonomous University of Baja California (UABC) diverse recycling initiatives have taken place since $1998^{1}$ but these have been focused on the logistics of recyclables separation. Solid waste characterization studies have also taken place at UABC in order to propose an integrated solid waste management program. Information campaigns for these initiatives had the objective to make clear how to use the different recycling bins, where these new bins were located and how separation should be made. Information was the same for all audiences in the organization and was delivered through an internet site, flyers, radio and TV spots and conferences. One common characteristic of previous recycling initiatives was that all were announced and promoted by people in top-management positions of the university. Other common thing among these programs was that they all depended on the participation of maintenance staff. One last element shared in previous programs was their financial dependence for the logistics and publicity of the programs. Despite the effort made in the information campaigns and in the logistics, those recycling programs in UABC did not bring effective results. Waste was not properly separated, bins were not used the way they were supposed to, people were not keen to participate in the programs, and finally, it was very difficult to sell the recyclables because of these problems.

\footnotetext{
${ }^{1}$ Arroyo, V., personal communication, 2006.
}

In view of the results of the previous recycling efforts, a different approach was used to promote and impel a new initiative to separate and recycle paper and cardboard at the Campus Ensenada of UABC. The study reported here has the objective to implement and evaluate the performance of a paper and cardboard segregation program in one of the campuses of the Autonomous University of Baja California. This program was planned and undertaken through a social marketing strategy [23, 24]. Based on the experiences of the initiative reported here, the program is expected to expand to all the campuses of $\mathrm{UABC}$ and later to other colleges and universities of Baja California. Finally these experiences could set ground for a school sector oriented waste management strategy.

\section{SOCIAL MARKETING APPROACH}

Advocacy messages commonly face the challenge of trying to change behavior by forcing consumers to confront some disconcerting reasons for the need to abandon the status quo. Ads or other message forms appealing for increased recycling are no exception [25]. According to Hopper and Nielsen [26] recycling is an altruistic behavior; and De Young [27] mentions that efforts to promote waste reduction and recycling behavior should focus on nonmonetary motives. The question then is how to appeal to non-monetary motives to make people participate in waste separation recycling programs? Social marketing offers an alternative approach to the typical information channels for recycling programs such as: flyers, TV spots, posters, stickers, etc. Community base social marketing is based upon research in the social sciences that demonstrates that behavior change in most effectively achieved through initiatives delivered at the community level, which focus on removing barriers to an activity while simultaneously enhancing the activities benefits.

Social marketing arose as a discipline in the 1970s, when Philip Kotler and Gerald Zaltman [28] realized that the same marketing principles that were being used to sell products to consumers could be used to "sell" ideas, attitudes and behaviors. Like commercial marketing, the primary focus is on the consumer-on learning what people want and need rather than trying to persuade them to buy what we happen to be producing. The application of marketing principles and techniques to promote a social cause, idea or behavior has been effectively used in many recycling programs [29-33]. Social marketing approach has been found to significantly contribute to the attainment of specific program objectives and goals. Implementing it, however, involves a decision by management to undertake a focused and purposive activity requiring the kind of support that is anchored on the belief that this approach in fact, can make a difference [32].

Social marketing has emerged as an alternative to promote environmentally friendly practices such as recycling $[31,34,35]$. It is a unique approach because it offers a framework for the people in need to promote behavioral changes in diverse establishments. Community-based social marketing also uses tools that have been identified as being particularly effective in fostering change. Although each of these tools on its own is capable of promoting sustainable behavior, the tools can often be particularly effective when 
used together. Key community-based social marketing tools include:

- Prompts: Numerous behaviors that support sustainability are susceptible to forgetting. Prompts can be very effective in reminding to perform certain activities remind people to engage in sustainable activities (e.g., a vehicle window sticker indicating that the driver does not idle);

- $\quad$ Commitment: According to McKenzie-Mohr \& Smith [23] in a wide variety of settings people who have initially agreed to a small request, have subsequently been found to be far more likely to agree to a larger request. These authors recommend having people commit or pledge to engage in sustainable activities through, for example, signing a pledge card to avoid unnecessary idling.

- Communication: Programs that intend to foster sustainable behavior should include a communication component. In this program were used short e-mail messages with relevant information about the progress of the recycling program such as quantities of cardboard an paper separated, punctual instructions on how to separate, and the e-mail and phone number of the people in charge. Special attention was paid to the recommendations of McKenzie-Mohr \& Smith [23] in relation to the usage of captivating information, credible sources, avoiding the use of threatening messages, use of massages easy to remember, among other.

- Removing external barriers: The behavior change strategies used in social marketing can have a significant influence upon the adoption and maintenance of behavior.

- Norms: Develop community norms that a particular behavior is the right thing to do; and,

- Incentives: Are used to reward people for taking positive actions, such as returning beverage containers, rather than fining them for engaging in negative actions. Incentives can be powerful levers to motivate behavior.

Social marketing starts with the selection of a "target behavior" and later uses a four stage process to encourage the desired change towards a sustainable behavior. These four stages are [23]:

\section{Identifying Barriers to a Particular Behavior}

Research indicates that each form of sustainable behavior has its own group of barriers [36-43]. To promote activities that support sustainability, barriers to these activities must first be identified. Community-based social marketing therefore begin by conducting the research that will help to identify these barriers. It is not unusual to uncover multiple barriers that are quite specific to the activity being promoted. Once the barriers have been identified, the next step is to develop a program that addresses each of them. Personal contact, the removal of barriers and the use of proven tools of change are emphasized in the program.

\section{Developing and Piloting a Program to Overcome these Barrier}

To ensure that the program will be successful, it should be piloted in a small segment of the community and refined until it is effective. The program is then implemented throughout the community, and procedures are put in place to continually monitor its effectiveness.

\section{Implementing the Program Across A Community}

The steps that make up community-based social marketing are simple but effective. When barriers are identified and appropriate programs are designed to address these barriers, the frequent result is that individuals and organizations adopt more sustainable activities, which is the cornerstone of healthier, more sustainable communities.

Social marketing is based in social sciences research and particularly in psychology that has identified a variety of effective tools to promote behavior change. These tools are more effective when used combined. The tools used in this research were the following:

\section{Evaluating the Effectiveness of the Program}

In order to know the degree of success of the strategies for change it is necessary to evaluate the implementation of the program by obtaining information on baseline involvement in the activity prior the implementation and at several points afterward.

\section{METHOD}

The paper and cardboard recycling pilot program reported here took place at the Campus Ensenada of the Autonomous University of Baja California, Mexico. The evaluation of the program was made during 16 months from January 2008 to May, 2009, July is not considered because is the summer vacation and no waste is generated during that time. The steps followed to implement the mentioned program were the ones proposed by McKenzie-Mohr and Smith [23], these are the following:

\section{Identifying Target Behavior}

The first step to implement the program starts with two questions. The first question that was addressed in this step was what behavior should be promoted? To decide which behavior to promote at UABC it was necessary to answer the question, what is the potential of an action to bring about the desired change? To answer this, a detailed analysis was made about the desired change. This analysis was made based on the previous waste management experiences at $\mathrm{UABC}$ and on the present day institutional context.

A second question that had to be answered in this stage was, who should the program address or target? To answer this question it was made a review of the results of a previously applied questionnaire aimed to detect the attitudes towards reducing, reusing and recycling waste. This questionnaire was applied to a sample group of the university community that included students, administrative staff, faculty and custodians.

\section{Identifying Barriers to a Particular Behavior}

To detect the barriers to separate cardboard and used paper three steps were followed: 
1. Literature review: Academic books and articles were reviewed in order to detect to most typical barriers encountered in other places when new waste management programs were implemented

2. Observation and interviews: Qualitative information was obtained through observation of the way people working or studying at UABC generate and disposes paper and cardboard. Twenty persons were interviewed (five secretaries, five students, five custodians and five professors). The objective of the interview was to recognize why they were handling their waste that way and if they had any knowledge about the implications of their behavior.

3. Survey: A survey was constructed, validated and applied to 30 people randomly chosen. The objective of the survey was to identify the attitudes towards waste management and the disposition to participate in a paper and cardboard separation program. It was also asked how they would prefer to receive information about a waste management program.

\section{Use of Tools for Behavior Change}

1. Commitment: For this program, diverse types of commitment were sought: written, verbal, public, group, actively involving a person.

2. Different prompts were used such as signs in the offices, signs near the recycling bins, and short written explanations about the characteristics of waste to be recycled.

3. Communication: Diverse communication strategies were used such as conferences, flyers, stickers, e-mail reminders and information messages. The first two were delivered through the work of social service students, the latter through the University mass e-mail service.

4. Incentives: Even though incentives have shown to have an important impact in a variety of programs to recycling, in this program incentives were not used because the program lacked financial support.

5. Based on the barriers detected in the previous stage (identifying barriers to a particular behavior) two main strategies were used:

a. Location of recycling bins in convenient places near the paper generation points.

b. Twice a week collection of the materials separated in the recycle bins. The collection was made by social service students.

\section{Design and Evaluation}

Once the barriers were identified and prioritized, the change tools that matched the barriers were selected. Feedback from the participants was obtained and latter the pilot program was launched in two faculties. The pilot program was functioning during 16 months, some failures were corrected, and then it was expanded to all the faculties of the campus.
To evaluate the general progress of the separation of paper and cardboard, the monthly quantities of these materials were recorded.

To evaluate the efficiency of the communication and information campaign a survey was made which included seven questions with five Likert scale values each, where 1 corresponded to total disagreement, 3 to a neutral position and 5 to a total agreement position. This survey was applied to 40 people in three different times: three, 12 and 16 months after the implementation of the program. The questions included in the survey were the following:

1. The waste that I generate is my responsibility

2. $\mathrm{UABC}$ is an institution that manage its solid waste properly

3. Paper separation program at UABC promotes a culture of environmental responsibility

4. I am willing to actively participate in the paper and cardboard separation program of UABC

5. Is easy and convenient to separate paper

6. I know the location of the paper bins

7. I am informed about the progress and changes of the paper and cardboard program at UABC

\section{RESULTS}

The results are presented in the same order as the steps presented in the methodology section.

\section{Identifying Target Behavior}

All previous waste programs at UABC presented an inadequate separation of waste; this problem was also identified by other waste management coordinators of other universities [9, 14, 44]. Thus the target behavior identified was "an adequate diversion of paper and cardboard". By adequate we refer to the separation of materials that do not include contaminants or other types of waste but the ones indicated by the program.

A second target behavior was the "correct disposition of paper and cardboard in the containers destined to deposit those materials". This was decided since in previous experiences of recycling in $\mathrm{UABC}$ one of the main problems was that although the generators of residues knew well the type residues that had to be deposited in recycling containers the disposal was incorrectly performed.

The objective population to which the campaign would go was academic and administrative personnel, the participation of students occurred indirectly. This was decided because the former generate more paper and cardboard in the campus and are the groups that can be monitored for longer periods. While students remain less time in the university facilities and leave after three or four years, so is more difficult to follow their recycling behavior.

\section{Identifying Barriers to a Particular Behavior}

The information found in literature agreed with the findings of this study as far as the barriers to make the 
desired change, in the discussion section are mentioned these. Table $\mathbf{2}$ shows a simple matrix that presents the perceived benefits and barriers as well as the behaviors that compete with the target behavior detected during the observations and interviews.

Table 2. Perceived Benefits and Barriers and Competing Behaviors (for Target Behavior 1)

\begin{tabular}{|c|c|c|}
\hline & $\begin{array}{c}\text { Target Behavior } \\
\text { Correct Separation } \\
\text { of Materials }\end{array}$ & $\begin{array}{c}\text { Competing Behavior 1 } \\
\text { Easy to Dispose All } \\
\text { the Materials Mixed }\end{array}$ \\
\hline \hline $\begin{array}{c}\text { Perceived } \\
\text { Benefits }\end{array}$ & Helps the environment & $\begin{array}{c}\text { No need to differentiate } \\
\text { types of waste }\end{array}$ \\
\hline $\begin{array}{c}\text { Perceived } \\
\text { Barriers }\end{array}$ & $\begin{array}{c}\text { Lack of time to } \\
\text { separate waste types }\end{array}$ & $\begin{array}{c}\text { Bad for the Environment } \\
\text { Costly disposition of } \\
\text { waste in landfill }\end{array}$ \\
\hline
\end{tabular}

Table 3. Perceived Benefits and Barriers and Competing Behaviors (for Target Behavior 2)

\begin{tabular}{|c|c|c|c|}
\hline $\begin{array}{c}\text { Target Behavior } \\
\text { Correct Deposition } \\
\text { of Materials in } \\
\text { Recycling Bins }\end{array}$ & $\begin{array}{c}\text { Competing } \\
\text { Behavior 1 } \\
\text { Everything is } \\
\text { Disposed in the } \\
\text { Same Bin }\end{array}$ & $\begin{array}{c}\text { Competing } \\
\text { Behavior 2 } \\
\text { Throwing } \\
\text { the Waste } \\
\text { from its Place }\end{array}$ \\
\hline \hline $\begin{array}{c}\text { Perceived } \\
\text { Benefits }\end{array}$ & $\begin{array}{c}\text { Helps the environment } \\
\text { Good image } \\
\text { Exemplary behavior }\end{array}$ & $\begin{array}{c}\text { No need to move to } \\
\text { the recycling bin }\end{array}$ & Saves time \\
\hline $\begin{array}{c}\text { Perceived } \\
\text { Barriers }\end{array}$ & $\begin{array}{c}\text { Lack of recycling bins } \\
\text { Lack of space for } \\
\text { recycling bins }\end{array}$ & $\begin{array}{c}\text { Bad for the } \\
\text { environment }\end{array}$ & Bad image \\
\hline
\end{tabular}

Tables $\mathbf{2}$ and $\mathbf{3}$ show the perceived benefits and barriers more frequently mentioned during the interviews. These results made evident that the strategies should be oriented to facilitate the process for material separation and disposition. To achieve these goals two different types of temporal disposal sites were placed to separate paper and cardboard: 1) primary sites and 2) secondary sites. The former were Gaylord boxes (47" x 36" x 50") which were intended for the temporarily store of considerable quantities of paper and cardboard. These boxes were located in sites protected from rain and wind but at the same time that were accessible (Fig. 1) for the deposition of material and for the collection.

The secondary deposit sites were located near the paper and cardboard generation sites, mainly inside offices or in corridors. For example for a group of cubicles a median size box was located in the corridor (Fig. 2). If the professors wanted and space was available, a small box was placed as well in his or her office (Fig. 3), so that they did not have to move to deposit any material. This was only made in the cases in which the box for paper did not represent a problem of space in the office.

The collection of paper in the secondary disposal sites was carried out by social service students. Students pickedup the materials and deposit them in the primary disposal sites. This way the perceived barriers mentioned by faculty and staff would be overcome. Each time the primary deposits were full, a recycling company was called to collect the materials.

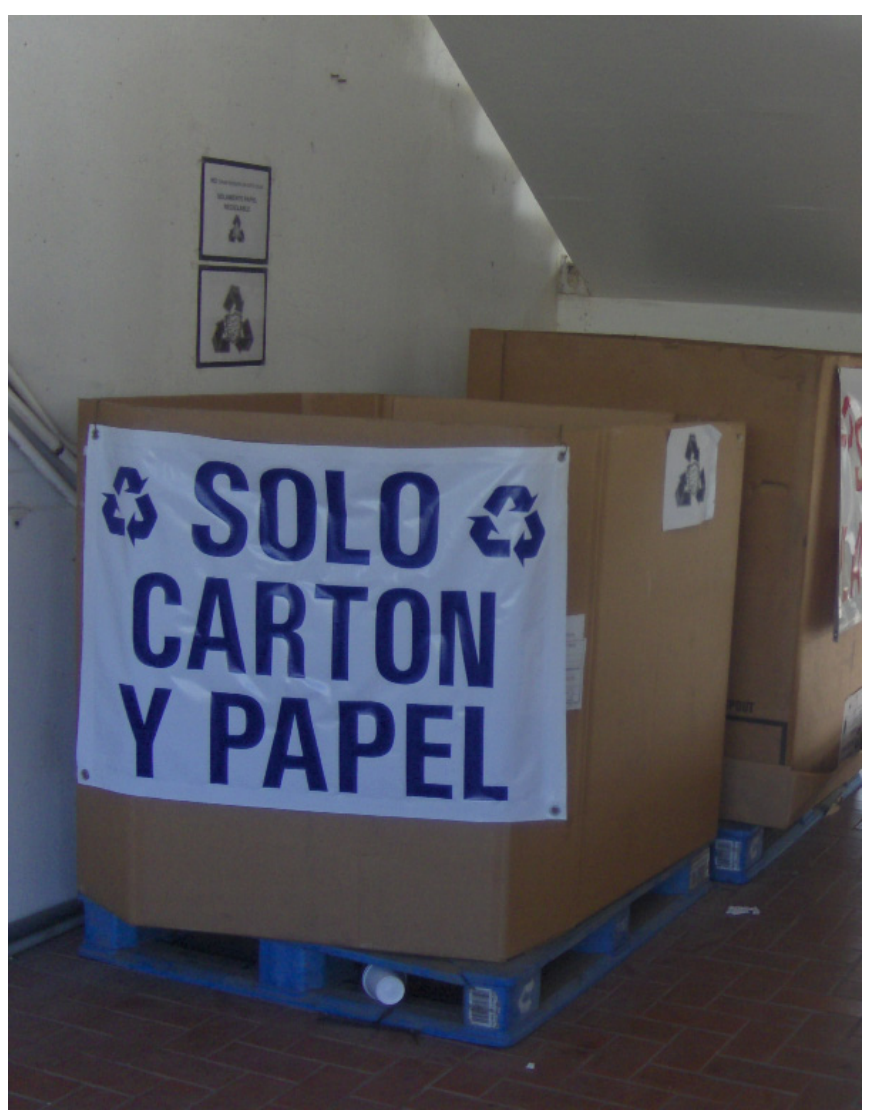

Fig. (1). Primary disposal sites for paper and cardboard.

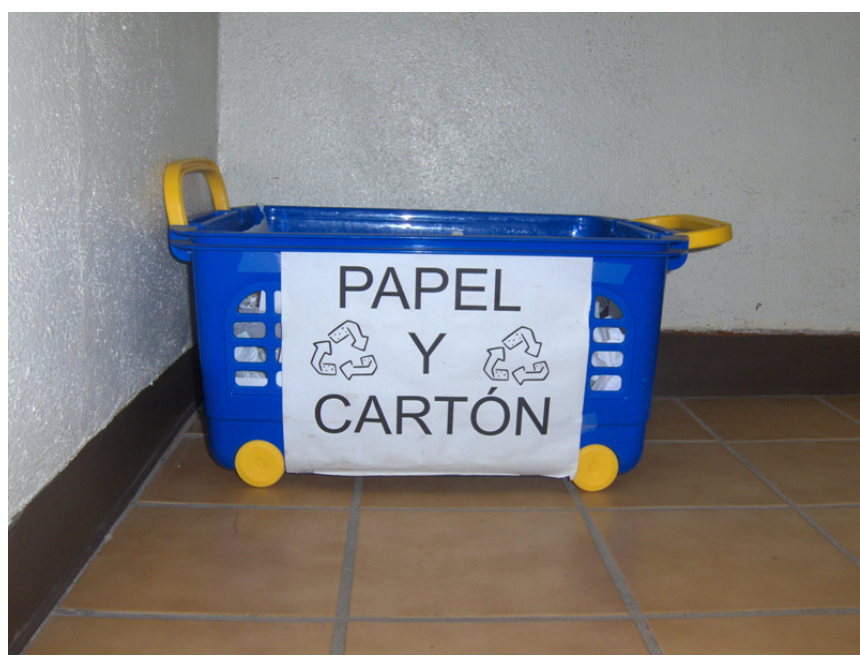

Fig. (2). Secondary disposal sites in corridors.

\section{Use of Tools for Behavior Change}

In this study the following tools were used:

- Verbal commitment was emphasized in offices, group commitment was pursued, people was actively involved, coercion was never used, people was helped to see themselves as environmentally responsible. This was made in 26 administrative offices, in the four faculties of the campus and in the two institutes. 
- Visual prompts were used in corridors, primary disposal sites and via e-mail. The prompts were mainly used to remind the types of material to be separated and the location of the temporal disposal sites.

- $\quad$ The communication system was through e-mail, this media was chosen because it can be massively delivered to the whole campus. The information delivered was focused on the quantities of materials diverted from the main waste stream, a short explanation of the program and a thank you note to let the people know that the success of the program was because of the community participation and commitment.

- The elimination of barriers consisted on the convenient location of the primary and secondary disposal sites and in the collection made by students. This way the participants would only have to correctly separate cardboard and paper and students would collect the materials from the generation site.

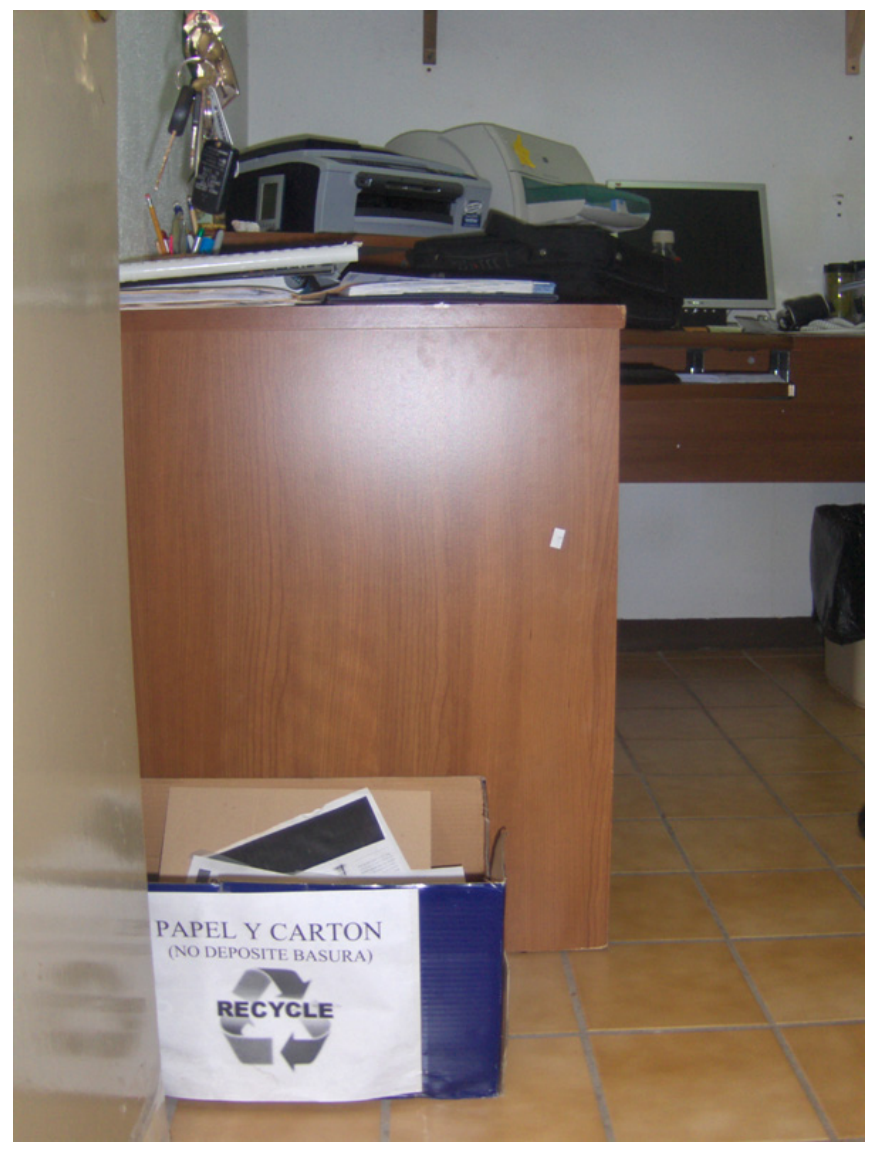

Fig. (3). Secondary disposal sites in cubicles.

\section{Evaluation}

Every two weeks social service students reported the conditions of use of primary and secondary disposal sites and the number of complaints received. This way any inconvenience or misuse of boxes could be corrected, and signs replaced.

A hard indicator of the progress of the paper and cardboard program was the monthly amount $(\mathrm{kg})$ of materials separated. For doing this the quantities of the materials diverted were recorded; (Fig. 4) shows the monthly quantities $(\mathrm{kg})$ of paper and cardboard in a 16 month period. The total amount for the 16 month period is $6,008 \mathrm{~kg}$ of paper and cardboard.

Fig. (4) shows the quantities of paper and cardboard have fluctuated during the evaluated period. The first two months present the lowest amounts of materials because the program then was present only in two faculties. During the first semester the highest amount was reach in April that coincided with the expansion of the program to all the campus. Also in April one of the campus faculties made an aggressive campaign involving a group of students inviting the university community to clean their offices and get rid of old notes and exams. The effect of this campaign lasted until May and decreased in June. The month of July reports no results because is the summer vacation period and no activity takes place at campus. The first year (from January to December, 2008) had a monthly average of $295 \mathrm{~kg}$; the next five months (January to May, 2009) had an average of 552 $\mathrm{kg}$. This difference shows an average increase of $87 \%$ the amount of the first year.

It is to be noted that the reported quantities were informed by the recycling company since we did not have the equipment to weigh the materials before they were collected by the company. Because the separation and collection of paper and cardboard were made in a single container, the data of both materials are reported together.

The survey to evaluate the efficiency of the communication and information campaign of the program showed progress. In Fig. (5) can be observed that the seven indicators improved with time, this means that a positive change in the perception of the program took place.

When the survey was applied for the first time (blue line) the values were low, principally in relation to the the willingness to participate in the program (question 4). In general it can be mentioned that the perception of participants in relation to their reponsability as waste generators changed positively (question 1), although a decrease of one unit is present for the last evaluation (greeen line). A positive trend was shown in the perception that $\mathrm{UABC}$ manage its solid waste properly (question 2 ). The perception that $\mathrm{UABC}$ promotes a culture of environmental responsibility (question 3 ) was at its higher value since the second time the survey was applied. The perception that is easy and convenient to separate paper (question 5) also improved, this indicates that people is realizing that this activity does not take much time and can be easily done. The knowledge of the location of the recycling bins (question 6) is a good indicator that the signs and promps are working well. Finally the survey showed that the people is informed about the progress of the paper and cardboard program (question 7), but special care must be paid here because the survey was applied just one day after the last information email was sent. In general (Fig. 5) shows a positive trend in most of the indicators, nevertheless more attention must be paid to the awareness campaingn in order to improve the perception of waste generators as responsible participants of the waste problem. 


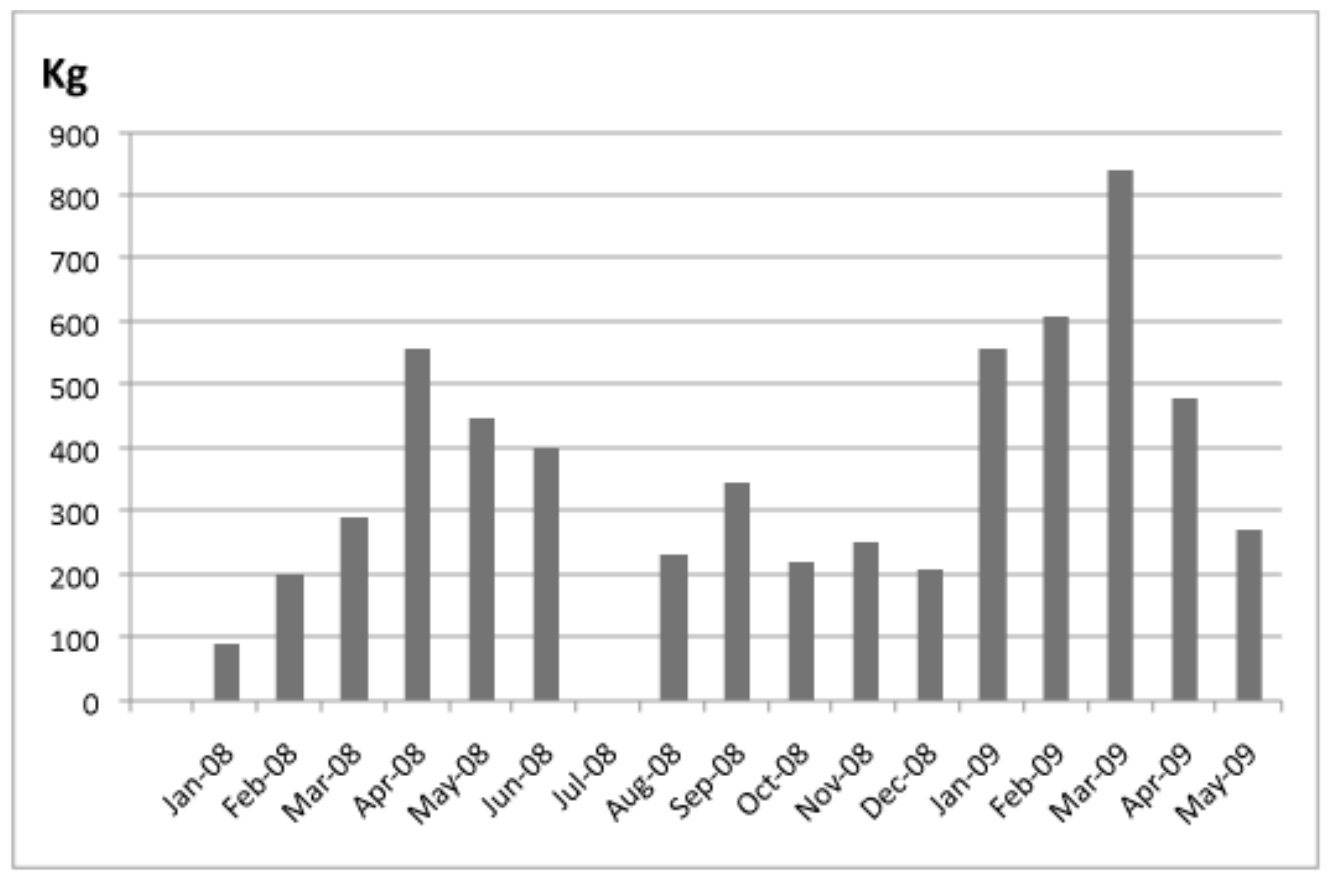

Fig. (4). Quantities (kg) of paper and cardboard generated in a 16 month period.

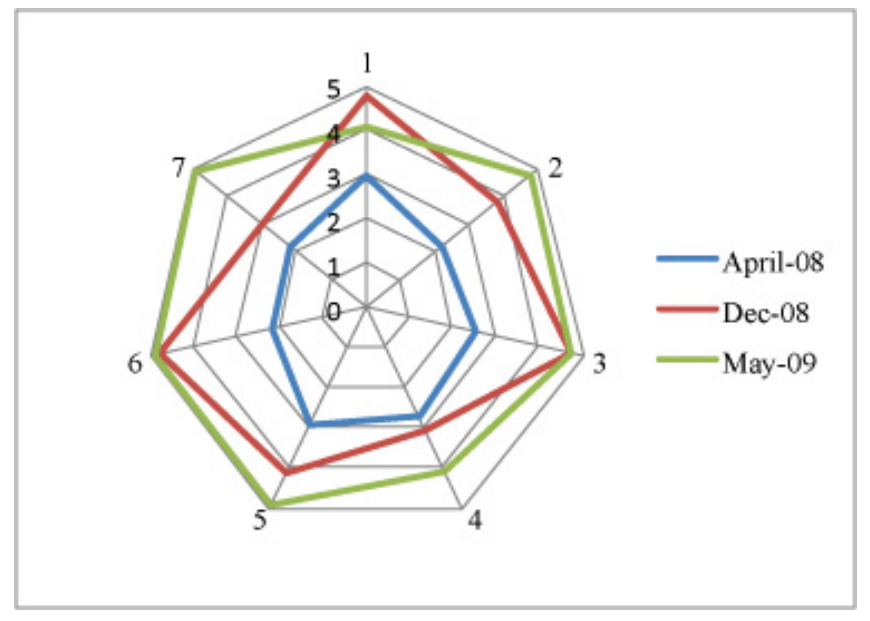

Fig. (5). Results of the survey in three different times.

\section{DISCUSSION}

Recycling programs contributes to institutional solid waste reduction objectives; leading community by practicing ethical and resposible waste management. Thus also special attention shoud be focused on the strategies used to involve and influence more people to participate in the program. At $\mathrm{UABC}$ the paper and cardboard recycling program is not mandatory, this is the reason why not all the staff, faculty and students are participating. Although, the authors are positive that more people will get involved in the program if social marketing strategies continue to be used.

Some social contexts may actively discourage the widespread adoption of recycling activities. Individual concern for the environment and individual resources such as education may not easily overcome contextual barriers to action. However, if the context is changed to facilitate the adoption of new behavior, the probability of individual action should increase because the effort required on the part of any single individual decreases. In the case reported here the context change was the convenient location of recycling bins and the materials collection made by students. Under these circumstances, recycling would require relatively little effort, and as a consequence, participation is further promoted more. This finding agrees with Taylor \& Todd [45] who found that a similar concept self-efficacy (the perceived ability to carry out the behavior), leads to perceived behavioral control and from there to a positive intention to recycle. This is also in accordance with Derksen \& Gartrell [46] in that the most important determinant of recycling behavior is access to a structured program that makes recycling easy and convenient. Amutenya, Shackleton and Whittington-Jones [13] also discuss the importance of removing the distance barriers by increasing the number of recycling bins which leads to a potential increase in recycling. Thøgersen [47] supports the above demonstrating the usefulness of social marketing approach for the promotion of recycling through the design of reverse distribution channels for recyclables.

Furthermore, a systematic, well-advertised program could create a new community norm favoring recycling. In accordance to this one way of encouraging a long-term recycling behavior is through information and dissemination techniques [13]. Community based social marketing (CBSM) applied to a social cause such as recycling, offers a good approach for dissemination and the delivering of information. In this sense, periodic prompts, information, and follow-up surveys should be an ongoing part of the program. In the case of the paper and cardboard recycling program of UABC this continuous approach has taken place and will continue to be. Nevertheless more attention should be paid to the time gaps where no students are present. At present no strategy is in place for the weeks when student finish their social service program and a new term starts. This could help to explain the reduction in paper and 
cardboard collected by the program during the inter-semester periods.

\section{CONCLUSIONS}

Clearly recycling is an essential element of any long-term solution to the problem of waste, and how to motivate full participation in recycling programs becomes of critical concern to recycling advocates. Community based social marketing (CBSM) as a framework to foster recycling is suited for university settings. A variety of CBSM strategies were employed at the Autonomous university of Baja California to address the issue of proper waste management.

Based on the results presented here it can be concluded that the paper and cardboard separation program of UABC is progressing. For the case reported here the social marketing tools proved to be effective to influence public behavior and this could be because it focused on the target audience's point of view, this made account of the emotional or physical barriers that may have prevented people from changing their behavior and not on coercion neither on fear campaigns that only have short time effects.

Although CBSM approach has been applied to different environmental programs internationally, the interesting issue found in this study is that this is not the first attempt to implement a waste management program at UABC. The difference now, compared to the previous waste management initiatives in this institution, is that the latter were led by top management authorities using the typical command chain way to impose new practices, in this case, new ways to deal with waste. The program reported in this paper did not depend on support from authorities nor from custodians. In this sense a bottom-up program was being promoted using a completely new approach.

To facilitate the initial steps towards change is positive because this makes people to easily "hook" on the proposed activities. Nevertheless it is imperative to also search for strategies that seek a community's deeper responsibility in waste management, not because it is easy to hook but because it is right to do it.

The paper and cardboard program of UABC is only the start of an integrated solid waste management program. Before including more categories of waste into the program (e.g. plastics or metals) an adjustment must be made to the follow-up of the quantities of material generated. A paper and cardboard separate record should be made to know the precise quantities of each material and have better indicators of the advancement of the program.

\section{ACKNOWLEDGEMENTS}

The authors would like to express their gratitude to all the social service students who participated in the paper and cardboard separation program during the reported period. The authors would also like to thank the staff, students and faculty who responded the surveys and interviews during the evaluation stage of this program.

\section{REFERENCES}

[1] D. Ferrer-Balas, H. Buckland, and M. Mingo, "Explorations on the University's role in society for sustainable development through a systems transition approach. Case-study of the technical University of Catalonia (UPC)", J. Cleaner Prod., vol. 17, pp. 1075-1085, 2009.

[2] M. Juárez-Najera, H. Dieleman, and S. Turpin-Marion, "Sustainability in Mexican Higher Education: towards a new academic and professional culture," J. Cleaner Prod., vol. 14pp. 1028-1038, 2006,.

[3] M. Lehmann, P. Christensen, M. Thrane, and T. Herreborg Jørgensen, "University engagement and regional sustainability initiatives: some Danish experiences ,"University engagement and regional sustainability initiatives: some Danish experiences, vol. 17, pp. 1067-1074, 2009.

[4] L. Velázquez, N. Munguia, A. Platt, and J. Taddei, "Sustainable university: what can be the matter?," J. Cleaner Prod., vol. 14, pp. 810-819, 2006.

[5] G. Zilahy, and D. Huisingh, "The roles of academia in Regional Sustainability Initiatives ," J. Cleaner Prod., vol. 17, pp. 10571066, 2009.

[6] F.S. Crofton, "Educating for sustainability: opportunities in undergraduate engineering," J. Cleaner Prod., vol. 8, pp. 397-405, 2000.

[7] A. Lidgren, H. Rodhe, and D. Huising, "A systemic approach to incorporate sustainability into university courses and curricula," $J$. Cleaner Prod., vol. 14, pp. 797-809, 2006.

[8] T. Ramos, "Development of regional sustainability indicators and the role of academia in this process: the Portuguese practice ," $J$. Cleaner Prod., vol. 17, pp. 1101-1115, 2007.

[9] C. Armijo-de Vega, S. Ojeda-Benítez, and M.E. Ramírez-Barreto, "Mexican educational institutions and waste management programmes: a University case study," Resour. Conserv. Recycl., vol. 39, pp. 283-296, 2003.

[10] T.C. Kelly, I.G. Masson, M.W. Leiss, and S. Ganesh, "University community responses to on campus resource recycling," Resour. Conserv. Recycl., vol. 47, pp. 42-55, 2006.

[11] I.G. Masson, A. Oberender, and A.K. Brooking, "Source separation and potential re-use of resource residuals at a university campus," Resour. Conserv. Recycl., vol. 40, pp. 155-172, 2004.

[12] I.G. Masson, A.K. Brooking, A. Oberender, J.M. Harford, and P.G. Horsley, "Implementation of a zero waste program at a university campus," Resour. Conserv. Recycl., vol. 38, pp. 257-269, 2003.

[13] N. Amuteya, C.M. Shackleton, and K. Whittington-Jones, "Paper recycling patterns and potential interventions in the education sector: A case study of paper streams at Rhodes University, South Africa," Resour. Conserv. Recycl., vol. 53, pp. 237-242, 2009.

[14] Florida State University, Recycling at Florida State University, Miami: Florida State University, 2007.

[15] C. Armijo-de Vega, S. Ojeda-Benítez, and M.E. Ramírez-Barreto, "Solid waste characterization and recycling potential for a university campus," Waste Manage., vol. 28, pp. S21-S26, 2008.

[16] R.M. Espinosa, S. Turpin, G. Polanco, A. De la Torre, I. Delfín, and I. Raygoza, "Integral urban solid waste management program in a Mexican university," Waste Manage., vol. 28, pp. S27-S32, 2008.

[17] L. Maldonado, "Reducción y reciclaje de residuos sólidos urbanos en centros de educación superior: estudio de caso," Revista Ingeniería, vol. 10, pp. 59-68, 2006.

[18] M.A. Felder, R.J. Petrell, and S.J. Duff, “A solid waste audit and directions for waste reduction at the University of British Columbia, Canada," Waste Manage. Res., vol. 19, pp. 354-365, 2001.

[19] O. Buenrostro-Delgado, Los residuos sólidos municipales: perspectivas desde la investigación multidisciplinaria, Morelia, Mich. Mexico: Universidad Michoacana de San Nicolás Hidalgo, 2001.

[20] C. Cortinas-De Nava, Hacia un Mexico sin basura, Ciudad de Mexico: Partido Verde Ecologista de Mexico, 2001.

[21] S. Ojeda-Benítez, C. Armijo-de Vega, and M.E. Ramírez-Barreto, "The potential for recycling household waste: a case study from Mexicali, Mexico," Environ. Urban., vol. 12, pp. 163-173, 2000.

[22] SEDESOL, Situación actual del manejo integral de los residuos sólidos en México, Mexico City: Sancho y Cervera, J, 1999.

[23] D. McKenzie-Mohr, and W. Smith, Fostering sustainable behavior: an introduction to community based social marketing, Gabriola Island B.C., Canada: New Society Publishers, 1999.

[24] P. Kotler, and N. Lee, Social Marketing: Influencing Behaviors for Good, Thousand Oaks, CA: Sage, 2007. 
[25] K.R. Lord, and S. Putrevu, "Acceptance of recycling appeals: the moderating role of perceived consumer effectiveness," J. Market. Manage., vol. 14, 1998, pp. 581-590.

[26] J.R. Hopper, and J.M. Nielsen, "Recycling as altruistic behavior: normative and behavioral strategies to expand participation in a community recycling program," Environ. Behav., vol. 23, pp. 195220,1991

[27] R. DeYoung, "Recycling as appropriate behavior: a review of survey data from selected recycling education programs in Michigan," Resour. Conserv. Recycl., vol. 3, pp. 253-266, 1990.

[28] P. Kotler, and G. Zaltman, "Social marketing: an approach to planned social change," J. Market., vol. 35, pp. 3-12, 1971.

[29] E.J. Cole, "A community-based social marketing campaign to green the offices at Pacific University: recycling, paper reduction and environmentally preferable purchasing," Antioch University, 2007.

[30] L.J. Shrum, T.M. Lowrey, and J.A. McCarty, "Recycling as a marketing problem: a framework fos strategy development," Psychol. Market., vol. 11, pp. 393-416, 1994.

[31] J. Tabanico and P.W. Schultz, "People aspect of recycling programs: community based social marketing," BioCycle, pp. 4144, 2007.

[32] C. Birgonia, Social marketing on solid waste management: the Jagna Experience, Philipines: EcoGov2, 2007.

[33] B.L. MacLennan, and R.L. McConnell, "Use what you have: strategies for developing a hybrid marketing approach," Proceedings of the International Conference on Waste Technology \& Management, Philadelphia, PA: Widener University, pp. 716$727,2007$.

[34] S. Ball, "Social marketing as a means to influence student behavior towards energy conservation," M. Sc., University of Mary Washington, 2008.

[35] O. Werder, "Influences on the recycling behavior of young adults: avenues for social marketing campaigns," Environmental Communication Yearbook, New York: Lawrence Earlbaum Associates, pp. 77-96, 2005.
[36] R. Ching, and R. Gogan, "Campus Recycling: Everyone Plays a Part," The Campus and Environmental Responsibility , San Francisco: Jossey-Bass, pp. 113-125, 1992.

[37] S.P. Hamburg, and S.I. Ask, "The environmental ombudsman at the University of Kansas," The campus and environmental responsibility, San Francisco: Jossey-Bass, pp. 55-63, 1992.

[38] M. Dhale, and E. Neumayer, "Overcoming barriers to campus greening,” Int. J. Sust. Higher Educ., vol. 2, pp. 139-160, 2001.

[39] R. Clugston and W. Calder, "Critical Dimensions of Sustainability in Higher Education," Sustainability and University Life, New York: Peter Lang, pp. 31-46, 1999.

[40] S.H. Creighton, Greening the ivory tower: Improving the environmental track record of universities, colleges and other institutions, Cambridge, MA: MIT Press, 1998.

[41] A.S. Allen, "Institutional environmental change at Tulane University," Tulane University, 1999.

[42] C.A. Bowers, The culture of denial: Why the environmental movement needs a strategy for reforming universities and public schools, Albany: State University of New York Press, 1997.

[43] M. Schriberg, "Toward sustainable management: the University of Michigan Housing Division's approach," J. Cleaner Prod., vol. 10, pp. 41-45, 2002.

[44] J. Keniry, Ecodemia: campus environmental stewardship at the turn of the 21st Century., Washington, DC.: National Wildlife Federation, 1995.

[45] S. Taylor, and P. Todd, "An integrated model of waste management behaviour: a test of household recycling and composting intentions," Environ. Behav., vol. 27, pp. 603-630, 1995.

[46] L. Derksen, and J. Gartrell, "The social context of recycling," Am. Sociol. Rev., vol. 58, pp. 434-442.1993.

[47] Thøgersen, Jhon. Facilitating recycling: reverse distriburion channel design for participation and support. Social Marketing Quarterly. vol. 4, pp. 42-55, 1997.

(C) Armijo-de Vega et al.; Licensee Bentham Open.

This is an open access article licensed under the terms of the Creative Commons Attribution Non-Commercial License (http://creativecommons.org/licenses/by$\mathrm{nc} / 3.0 /$ ) which permits unrestricted, non-commercial use, distribution and reproduction in any medium, provided the work is properly cited. 